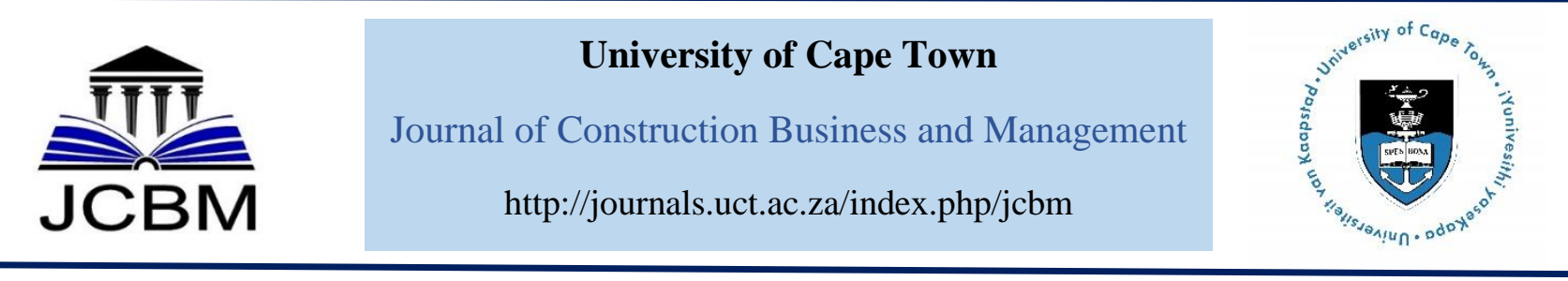

\title{
Exploring the effects of positive organizational behaviour (POB) models on occupational eustress amongst construction employees
}

\author{
A. C. Ogwueleka ${ }^{1}$ and D.I. Ikediashi ${ }^{2}$ \\ ${ }^{1}$ Department of Quantity Surveying, University of Uyo, Nigeria \\ ${ }^{2}$ Department of Building, University of Uyo, Nigeria
}

Received 11 January 2021; received in revised form 27 Feburary 2021, 27 July 2021 and 30 August 2021; accepted 5 September 2021. https://doi.org/10.15641/jcbm.5.1.1041

\begin{abstract}
The general perspective of organizational behaviour (OB) has been characterized more by negativity than positively. The introduction of a positive approach into $\mathrm{OB}$ is known as positive organizational behaviour (POB), which focuses on employees' positive emotions and strengths to enable them to thrive and reinforce the organization. The study assesses the effects of POB constructs on eustress amongst construction employees in Nigeria. Data were collected from 326 respondents practising in the construction firms using a quantitative survey and analyzed using both descriptive and inferential surveys, including structural equation modelling (SEM). The study identified five constructs of POB models and five parameters of eustress that have a significant influence on eustress. The study focuses on identifying the areas that can propel positive mental health among construction employees to improve their performances and increase work productivity. Therefore, it recommends that construction stakeholders should consider adopting company policies that can drive their implementations.
\end{abstract}

Keywords: Construction employees, distress, occupational eustress, positive organizational behaviourdelivery.

\section{Introduction}

Today's psychology movement has dramatically shifted from researching what is wrong with people and how to fix it to make peoples' lives more productive and fulfilling by nurturing their talents (Luthans, 2002). This prompted the earlier adoption of positive approach into psychology as positive psychology by well-known research-oriented psychologists such as Seligman and Csiksentmihalyi (2000), Diener (2000), Peterson (2000), and Synder (2000)]. Positive psychology (PP) is focused on maximizing peoples' strengths. Seligman (2002) defines PP as the study of positive emotions and the strengths that enable individuals and communities to thrive. There exists a high demand for the improved work performance of which employees' well-being plays a role. This provides the need to formulate frameworks and models to manage employees' capabilities toward improved work performance. The application of positively-oriented models to foster human strengths is targeted towards reinforcing the organization.

Luthans (2002) argues that previously the general perspective in organizational behaviour (OB) has been characterized more by negativity than by positivity, for example, more focus on stress and burnout than eustress, and dysfunctions; hurdles and inadequacies of managers rather than their puissance and capabilities for development and improving performance. OB studies the "behaviour, attitudes, and performance of people in organizations" (Dailey, 2016). This field of study emphasizes how employees' work contributes to or lowers an organization's overall project success and work productivity (Dailey, 2016). PP is integrated into the study of organizational behaviour to promote the employees' well-being and organizations towards improved performance; this is known as positive organizational behaviour (POB) (Seligman \& Csikszentmihalyi, 2000). McHugh (2001) emphasizes that the application of POB

\footnotetext{
${ }^{1}$ Corresponding Author.

Email address: amakaogwueleka@gmail.com

(C2021The Author(s).Published by UCT Library. This isan open access article under theCC BY 4.0 license. 
increases the employees' commitment at work and thereby decreases the risk of losing talented ones.

Likewise, stress management has been studied extensively, but the majority of research works focus on negativity. Previous studies on stress management have identified strategies of coping with stress (Chinyio et al., 2018); factors affecting stress and stressors ( $\mathrm{Ng}$ et al., 2005; Leung et al., 2012); and managing occupational stress amongst construction professionals (CIOB, 2006; Leung et al., 2010). Several written works show that work stress is rooted in psychology $(\mathrm{Ng}$ et al., 2005; Leung et al., 2010). This paper will not consider recapturing them but rather focus on assessing the effects of psychology capabilities adopted for this study as POB models on positive stress at the workplace. Stress is an inevitable element of human life, but the changing trends in stress management research have advocated a focus on positivity. A positive state of stress is known as eustress, while the negative aspect denotes distress (Matejek, 2019). This study focuses on the positive aspect of stress, which is eustress. It is important to note that the focus on positivity is based on the recent shift in stress management. The question is, why do we dwell on negativity while positivity can promote better work balance and well-being of employees? Jones (2016) defines eustress as a "positive reaction to stress that generates within us a desire to achieve and overcome a challenge" (Jones, 2016). This produces positive feelings amongst workers, resulting in increased performance and a general sense of well-being and contentment.

The ability to manage the stress associated with work conditions is influenced by cognitive and behavioural efforts that an individual exerts on it (Chinyio et al., 2018). When stressful conditions at work are not adequately managed, it influences the interpersonal relationships amongst project team members and organizational relationships, which will affect work performance (Leung et al., 2003). The study aims at assessing the effects of POB models on occupational eustress amongst construction employees in Nigeria. The adoption of POB models is still in its infancy, although studies have advocated that employees' positive responses will contribute to a higher level of eustress (Tavakoli, 2010).

\section{Literature review}

\subsection{The POB models}

The recent positive emphasis in organizational behaviour focuses on building human strength by promoting their state-like characteristics within an organization. This allows the psychological resource capabilities to be measurable and open to evolution, resulting in improved performance. Luthans (2002) proposed five psychological constructs for POB models, which are self-efficacy (confidence), hope, optimism, subjective well-being (happiness), and emotional intelligence. Whereas four positive constructs known as psychological capital or PsyCap were recommended by Luthans and Youssef (2007) for assessing the positive psychological state in human capital, these are hope, resilience, optimism, and self-efficacy. These positive psychological constructs are explained as follows:

\subsubsection{Self-efficacy}

Bandura (2012) defines self-efficacy as 'peoples' judgments of their capabilities to organize and execute courses of action required to attain designated types of performance". Luthans (2002) also describes self-efficacy as confidence; this can further be explained as believing in one self's ability to control a person's attitudes towards the social environment. Previous studies have shown that self-efficacy positively correlates with goal aspirations/attainment, job satisfaction, and performance (Bandura, 2000; Judges et al., 2001; Harter et al., 2002). Four sources of self-efficacy are identified as past performance, vicarious experience, verbal persuasions, and emotional clues (Lunenberg, 2011). The study adopts the ten measures of self-efficacy identified by Schwarzer and Jerusalem (1995) for data collection.

\subsubsection{Hope}

This is defined as a positive motivational scale that can be acquired by applying both aspired will-power goals and mapping out routes to achieve targets (Ogwueleka and Ogbonna, 2018). This aspired will-power involves setting goals and developing the driving force while mapping out routes to achieve targets involves providing pathways for achieving such goals and overcoming barriers. An assessment tool known as Adult Dispositional Hope Scale (ADHS) was developed by Synder et al. (1991), consisting of twelve questions to measure hope. The hypothetical question for this research was restructured from the measures.

\subsubsection{Resilience}

It is defined as "the developable capacity to rebound or bounce back from adversity, conflict, and failure or even positive events, progress and increased responsibility" (Luthans, 2002). The construct promotes the competence of individuals to cope successfully with adversity or uncertainty in the work environment. There exists a positive correlation between psychological resilience and psychological well-being (Rees et al., 2015). Therefore, the workplace climate has an important role to play in fostering resilience among employees. Four factors influencing resilience in the workplace were identified as an individual, individual jobs, teams, and organizations (Australian Government Comcare, 2014). For this study, the four identified factors were structured into a hypothetical question to measure resilience in the workplace.

\subsubsection{Optimism}

McCann (2015) attributes optimism as positive thinking, which confers eagerness to succeed in all endeavours. This is a belief that the outcomes of events will be favourable; or in other words, this involves thinking and feeling optimistic about the future. That does not mean that stress is not inevitable, but the approach towards a stressor is usually in a productive manner. An individual with a mindset of optimism views the world more productively and displays a positive thinking lifestyle, with greater control perception. This study restructured the five shortcomings of optimism and their remedies as identified by Smith (2015) into a research question for data collection. 


\subsubsection{Subjective well-being}

This refers to how people experience and evaluate their lives and specific domains and activities (National Research Council, 2013). It is a subset of positive psychology that captures the judgment of overall life satisfaction, including cognitive judgment and affective reactions. Subjective well-being (SWB) allows for the evaluation of a person's typical emotional experience along with life satisfaction. This provides a balance between one's behaviour/notions and the surrounding. The satisfaction with life scale was developed by one of the world's foremost SWB researchers, Professor Ed Diener, in 1985. The scale consists of 48 items, and this was later reduced to 5 items using factor analysis (Diener et al., 1985). This scale is restructured into a research question for data collection.

\subsubsection{Emotional intelligence}

Emotional intelligence (EI) is considered an important aspect of one's life because it deals with the ability to read other people's signals and react appropriately to them. Zeidner et al. (2009) define EI as the ability to perceive, understand, and regulate one's own emotions and also the emotions of others. Over the years, research has linked EI to positive life outcomes and improved mental and physical health (Martins et al., 2010). There exist several methods used to assess the different levels of EI, in which any of them may fall into either one of two types, namely: self-report tests or ability tests. This study focuses on construction personnel. Therefore the self-report test is considered suitable for data collection. This allows for respondents to rate their behaviours unlike-ability tests that a third party administers. For this study, the five categories of EI were adopted for self-report tests: selfawareness, self-regulation, motivation, empathy, and social skills and a research question was formulated to assess them.

\subsection{Stress management: Eustress versus Distress}

Work pressure can be considered either safe or threat, depending on an individual's coping abilities. An individual may have the coping abilities to perceive a medium level of work pressure, while the others may lack the coping abilities to manage expectations placed on them; this can lead to stress. Over the years, there exists the notion that stress is unhealthy and can lead to anxiety and depression ( $\mathrm{Li}, \mathrm{CaO} \& \mathrm{Li}, 2016)$. The negative perception of stress influences our physiological responses that lead to distress, while when positively perceived, it results in eustress. Some researchers argue that stress is not always bad for individuals (Pandey, 2005). Some level of stress is required to inspire and energize people in organizations.

Notwithstanding, the individual's subjective judgment influences his/her capability to cope with it. Quick et al. (2010, citing Lazarus \& Folkman's, 1984) on the study of cognitive appraisals of stressors, emphasize that challenges are considered eustress while threats are referred to as distress. They may co-occur, even as a result of the same stressor. Simmons (2000) further illustrates stress using the holistic model of bathtub analogy. He argues that the two faucets (distress and eustress) are necessary to get the water level and temperature right.
The new trend of stress management has advocated how to manage stress positively. Some researchers have promoted a preventive approach that focuses on preventing individual and organizational distress and promoting health (Haynes \& Love, 2004; Pandey \& Gaur, 2005). Therefore, it is important to note that healthy employees will eventually form productive teams that will result in healthy organizations. An organization with positive mental health provides a good work environment for its employees to maintain work-life balance and healthy well-being (Pandey, 2005). In examining what constitutes healthy individuals, earlier researchers stipulate that it goes beyond the absence of disease and disorder (pathogenesis) to understanding the true potential of an individual in terms of health and well-being (salutogenesis) (Antonovsky, 1987). Pandey and Gaur (2005) state that positive mental health represents a state of well-being, where an individual can overcome the normal stresses of life and be productive and fruitful in one's endeavour and contribute to his/her community.

As earlier stated, stress is inevitable; therefore, there is a need to create a work environment where workers will be willing to cope with it and remain productive. It is important to note that the experience of stress is conditioned by an individual's perception of control of the stressor; this can determine the behavioural, physical, and psychological outcomes of such an individual. The advocacy for positive mental health is to enable an individual to have control over the stressor. Control can be defined as “a person's agency and capacity to make choices: (Moore, 2016). The ability to make choices is rooted in whether the individual has developed a mindset equipped to deal with challenges rather than fear them. The subjective well-being (self-evaluation) is prone to cognitive reflection, which includes reflective appraisals of one's life and domains of life, such as work. The positive state of one's domain will generate eustress; this is targeted towards preventing and resolving distress. Those who experience eustress regularly are bound to reap several positive health benefits. Indicators of eustress are identified as positive affect, meaningfulness, manageability, engagement, and positive emotions (Nelson \& Simmons, 2003; Simmons \& Nelson, 2007; Little, Simmons, \& Nelson, 2007).

\section{Conceptual Framework/ Hypothesis Development}

As previously mentioned, the integration of $\mathrm{POB}$ models to occupational eustress within the construction sector is still in its infancy (Nangia \& Chaturvedi, 2015). Stress causes both physical and psychological harm. Therefore, managing stress at the workplace requires identifying the stressors at work, assessing and managing them. Stress at work does not always lead to distress, where associated challenges are effectively dealt with. The cognitive behaviour of an individual influence their ability to cope with any challenge, where an individual perceives the stressor as a challenge that can be conquered, then it becomes positive stress. This positive perception of stress motivates employees to be more productive. Stress is good, where the individual possesses the coping abilities to manage expectations and demands placed on him/her at the workplace (Haynes \& Love, 
2004). Eustress is a key factor in motivating employees to actualize improved performance and enhance job satisfaction (Nangia\& Chaturvedi, 2015). Previous studies have examined the relationship between job stress and job performance (Haynes \& Love, 2004; Nangia \& Chaturvedi, 2015). Their findings revealed that workplace stress significantly influences employee performance; this may incur psychological, physiological, and financial costs for both employees and the organization. Likewise, POB characteristics are aimed at protecting individuals at the workplace by helping employees to be able to defend their existence overcome challenges. At the conceptual level, this study proposes a linear relationship between POB models and eustress. From the literature review, six psychological constructs for POB models were identified, and five indicators for eustress were also mentioned. The conceptual framework is illustrated in Figure 1, while the research hypothesis is shown below.

Hypothesis one: Positive organizational models have a significant influence on eustress.

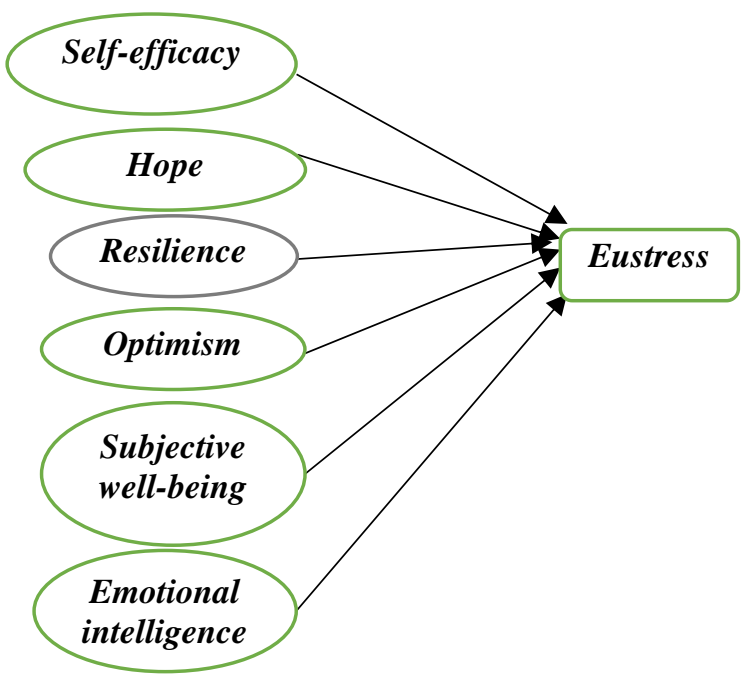

Figure 1: Conceptual framework

\subsection{Research Methods}

\subsection{Sample characteristics}

There are two types of sampling methods in a research survey: probability sampling and non-probability sampling. Probability sampling allows for multi-source information of the entire population due to its random selection procedure (Hamed, 2016). The study adopts a probability sampling method based on randomness and probability theory and a non-probability sampling technique for sample selection. The first is used to identify the sample frame, and the latter is adopted for selecting the respondents of sample size from the sample frame.

The study covers the sample frame of three major states in Nigeria, including Port Harcourt, Lagos, and Abuja. The target population comprises construction personnel who have executed commercial or public infrastructure projects or both. They include Quantity Surveyors, Builders, Engineers, Architects, Project Managers, and Foremen employed by registered construction companies (grade A to C) with the Federal Ministry of Works and Housing in the three selected states. The sample size of 375 was adopted for this study using Monte Carlo Simulation.

\subsection{Data collection procedure}

The study adopts field survey methodology to uncover the effects of POB models on occupational eustress amongst construction employees. Surveys through questionnaires were effective because of the relative ease of obtaining standard data appropriate for achieving the research aim (Ogwueleka, 2011). A drafted copy of the questionnaire was initially developed, and a pilot study was conducted using a selected group of experts and senior practitioners within the construction industry. Saunder et al. (2009) suggest that the use of content validity ensures that the questions are clear, relevant, and free of ambiguity. The questionnaire was revised based on the suggestions made during the pilot study. The face-toface contact method of questionnaire distribution was adopted to increase the response rate and improve reliability. A total number of six field assistants who were university students in the related disciplines during the survey period were mobilized for the field survey, and also one-day workshop training was organized for them.

An introductory letter was first sent to the organizations to indicate their willingness to participate, followed by questionnaire administration to the selected respondents. A total number of 375 questionnaires were administered, the selected respondents were given three weeks to respond. An additional one week was given to those who could not respond within the period. After the survey period (September - October 2019), 326 valid responses were returned and computed for data analysis representing a response rate of 87 per cent.

\subsection{Measures/variables}

The study measures two key variables, which are POB constructs and construction eustress. In order to achieve this, the questionnaire was divided into three parts. Part 1 presents the background information about the respondents, while part 2 assesses the effects of POB constructs amongst respondents. These POB constructs are self-efficacy, hope, resilience, optimism, subjective well-being, and emotional intelligence. A five-point Likert scale was adopted in measuring each construct with different parameters.

Table 1: Compiled POB constructs and their measures

\begin{tabular}{|c|c|}
\hline Variables/Codes & POB measures \\
\hline Self-efficacy & $\begin{array}{l}\text { I am confident that I could deal } \\
\text { effectively with unexpected events. }\end{array}$ \\
\hline Hope & $\begin{array}{l}\text { I can attain any goals that I set for } \\
\text { myself at my workplace. }\end{array}$ \\
\hline Resilience & $\begin{array}{l}\text { My work environment can influence } \\
\text { my ability to bounce back. }\end{array}$ \\
\hline Optimism & $\begin{array}{l}\text { There is a way out in any challenge } \\
\text { (problem-solving initiative) }\end{array}$ \\
\hline $\begin{array}{l}\text { Subjective well- } \\
\text { being }\end{array}$ & $\begin{array}{l}\text { In most ways, my life is close to my } \\
\text { ideas. }\end{array}$ \\
\hline $\begin{array}{l}\text { Emotional } \\
\text { intelligence }\end{array}$ & $\begin{array}{l}\text { I usually anticipate, recognize, and } \\
\text { meet clients' needs. }\end{array}$ \\
\hline
\end{tabular}

For self-efficacy, hope, and emotional intelligence, a scale of $1=$ definitely false to $5=$ definitely true was considered, resilience and optimism were measured with a scale of $1=$ not influential to $5=$ highly influential, while subjective 
well-being was measured with a scale of $1=$ strongly disagree to $5=$ strongly agree. Part 3 examines the influence of indicators of occupational eustress on construction employees. The indicators are positive effect, meaningfulness, manageability, engagement, and positive emotions. The respondents were asked to indicate their levels of agreement using a five-point Likert scale of $1=$ never to $5=$ always. Both variables and their measures are presented in Tables 1 and 2 .

Table 2: Indicators of occupational eustress and their measures

\begin{tabular}{ll}
\hline Variables/Codes & Eustress measures \\
\hline Positive effect (Z1) & $\begin{array}{l}\text { My efforts have had a positive } \\
\text { impact on my organizational } \\
\text { performance. }\end{array}$ \\
\hline Meaningfulness (Z2) & Do I find my work interesting? \\
\hline Manageability (Z3) & $\begin{array}{l}\text { I am always confident of my } \\
\text { abilities and skills for my work. }\end{array}$ \\
\hline Engagement (Z4) & $\begin{array}{l}\text { Does my work support the } \\
\text { services of my employer? }\end{array}$ \\
\hline Positive emotions (Z5) & $\begin{array}{l}\text { I am always on the right track at } \\
\text { my workplace. }\end{array}$ \\
\hline
\end{tabular}

\subsection{Structural equation modelling (SEM)}

SEM is a powerful statistical tool that combines both confirmatory factor analysis (CFA) and structural models for a simultaneous statistical test. It permits the measurement of several variables and inter-relationships simultaneously (Hoe, 2008). SEM is adopted in this study to test the proposed hypothesis. There are several indices of goodness-of-fit of the model. Researchers in SEM recommend that it is ideal to observe more than one of the indicators in evaluating models (Bentler \& Wu, 2002; Hoe, 2008). The commonly applied fit indices and their thresholds are X2 /df (ratio of 3 or less), RMSEA $(<0.08$ indicates acceptable fit), and CFI/NNFI ( $>0.09$ indicates good fit) (Hoe, 2008; Chen et al., 2008). The covariancebased SEM calculation is executed using AMOS 21.0, a professional software program designed for SEM analysis.

\section{Data analysis/Interpretation}

Initially, descriptive statistics were used to calculate the proportion of categorical variables, as shown in Table 3. The collected data from part two were screened using SPSS Missing Value Analysis Expectation Maximisation and Amos Mahalanobis distance (D) statistics to test for missing data. Kline (2010) suggested that missing data should be treated to prevent negative influence on correlation and regression weights. The result reveals two missing data, and they were substituted by mean for each measured variable. Nunnally and Bernstein (2007) emphasize that it is important to determine Cronbach's alpha coefficient when adopting the Likert scale on a questionnaire. Cronbach Alpha analysis was used to test if all the measured variables contribute to their corresponding latent variables. To confirm whether all the items on the questionnaire contribute to good internal consistency, the items were cross-examined to check if any value is above the overall coefficient means. The overall Cronbach alpha coefficient for the variables is 0.92, while none of the two groupings has a Cronbach alpha value of less than 0.8 .

Table 3: Demographic characteristics of respondents

\begin{tabular}{lcc}
\hline Characteristics & $\begin{array}{c}\text { Sample } \\
\text { size (n) }\end{array}$ & $\begin{array}{c}\text { \% of } \\
\text { respondents }\end{array}$ \\
\hline Professional roles & & \\
Quantity Surveyors & 78 & 24 \\
Builders & 48 & 15 \\
Engineers & 74 & 23 \\
Architects & 36 & 11 \\
Project Manager & 39 & 12 \\
Foreman & 51 & 15 \\
\hline Years of work experience & & \\
0-5 & 103 & 31 \\
6-15 & 126 & 39 \\
16-25 & 72 & 22 \\
Above 25 & 25 & 8 \\
\hline Educational background & & \\
Technical college certificates & 48 & 15 \\
First Degree certificates & 228 & 70 \\
Second Degree certificates & 50 & 15 \\
Total & $\mathbf{3 2 6}$ & $\mathbf{1 0 0}$ \\
\hline
\end{tabular}

Part two is analyzed using SPSS 19.0 (IBM Corp, Armonk, NY) and AMOS 21.0 software. The SEM relationship mode path diagram was constructed, and the hypothetical model was analyzed to determine whether the model is a good fit. The first step involves using confirmatory factor analysis to confirm the validity of the scale, and the second step includes adopting Maximum Likelihood to estimate the causal relationship of the research model. The initial result indicates a lack of fit between the proposed model and data. The model was modified twice using modification indices provided by AMOS software. The initial and final model fit indices are shown in Table 4; the chi-square value is 101.151 $[\mathrm{P}<0.000]$, while values of the other eight metrics were considered good after modification.

Table 4: Result of the Goodness of fit measures

\begin{tabular}{lccc}
\hline Goodness of fit measures & Criteria for assessment & Hypothetical model & Revised model \\
\hline $\mathrm{X}^{2} /$ degree of freedom & $<5$ & 3.101 & 2.975 \\
RMSEA & $<0 . .08$ & 0.870 & $0 . .078$ \\
Comparative Fit Index (CFI) & $\geq 0.90$ & 0.781 & $0 . .910$ \\
RFI & $\geq 0.90$ & 0.696 & 0.890 \\
Parsimonious Normed of Fit Index & $\geq 0.50$ & 0.743 & 0.641 \\
PCFI & $\geq 0.50$ & 0.645 & 0.749 \\
Normed Fit Index (NFI) & $\geq 0.90$ & 0.931 & 0.922 \\
IFI & $\geq 0.90$ & 0.897 & 0.934 \\
\hline
\end{tabular}


Figure. 2 shows the final model and its correlation coefficient, and Table 5 presents the parameter estimation of the final Structural Equation Model. The one-tailed significance $(p<0.05)$ is used to determine the impacts of latent factors on one another. From the results, all the positive organizational behaviour models positively influence eustress except resilience, while eustress can be significantly predicted by positive affect, meaningfulness, manageability, engagement, and positive emotions.

Table 5: The parameter estimation of the final Structural Equation Model

\begin{tabular}{cccccc}
\hline Route of path & $\begin{array}{c}\text { Standardized } \\
\text { coefficients }\end{array}$ & $\begin{array}{c}\text { Unstandardized } \\
\text { coefficients }\end{array}$ & $\begin{array}{c}\text { Standard } \\
\text { error }\end{array}$ & P-value & Interpretation \\
\hline $\mathrm{SE} \rightarrow$ Eustress & 0.35 & 0.18 & 0.037 & $<0.001$ & Supported \\
$\mathrm{H} \rightarrow$ Eustress & -0.20 & -0.11 & 0.046 & 0.016 & Supported \\
$\mathrm{R} \rightarrow$ Eustress & 0.11 & 0.05 & 0.028 & 0.089 & Rejected \\
$\mathrm{P} \rightarrow$ Eustress & -0.17 & -0.08 & 0.030 & 0.011 & Supported \\
$\mathrm{SWB} \rightarrow$ Eustress & 0.15 & 0.08 & 0.034 & 0.022 & Supported \\
$\mathrm{EI} \rightarrow$ Eustress & 0.24 & 0.11 & 0.033 & $<0.001$ & Supported \\
Eustress $\rightarrow \mathrm{Z} 1$ & 0.53 & 1.00 & - & $<0.001$ & Supported \\
Eustress $\rightarrow \mathrm{Z} 2$ & -0.25 & -0.40 & 0.128 & 0.002 & Supported \\
Eustress $\rightarrow \mathrm{Z} 3$ & 0.42 & 0.79 & 0.184 & $<0.001$ & Supported \\
Eustress $\rightarrow \mathrm{Z} 4$ & 0.54 & 0.99 & 0.195 & $<0.001$ & Supported \\
Eustress $\rightarrow \mathrm{Z} 5$ & 052 & 0.95 & 0.205 & $<0.001$ & Supported \\
\hline
\end{tabular}

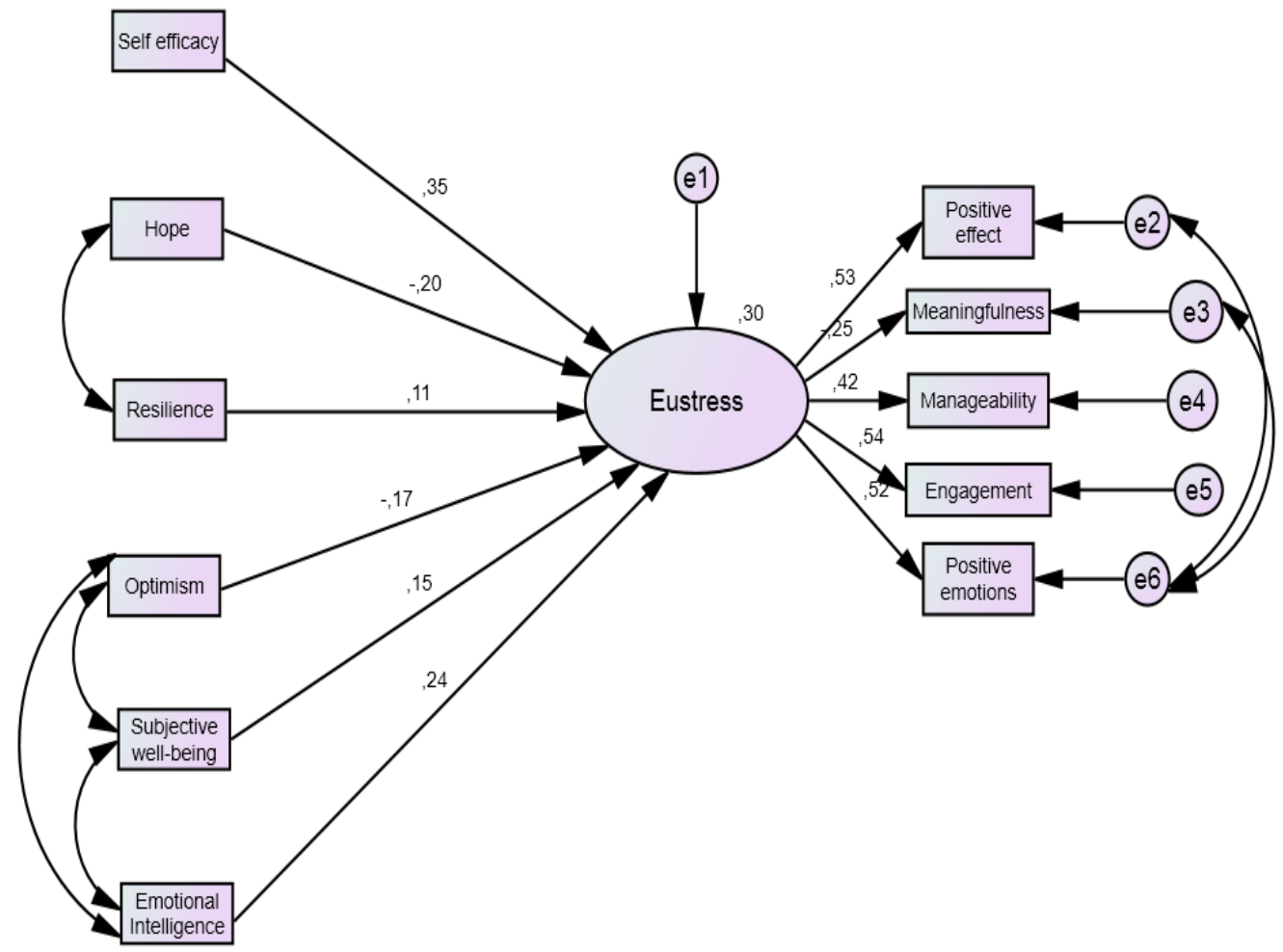

Figure 2: The final model and its correlation coefficient

\section{Discussion}

The structural component of the model suggests that the identified five constructs of POB models are important parameters to measure eustress among construction employees. These parameters are self-efficacy, hope, optimism, subjective well-being, and emotional intelligence. As earlier stated, eustress is viewed as when someone displays a positive reaction over an incident, with a willingness to overcome such a challenge. The measure of "I am confident that I could deal effectively with unexpected events" is used to test the influence of self-efficacy on eustress. The result shows that there is a significant level of influence on eustress. This is in line with the study conducted by O'Sullivan (2011), which emphasizes that when eustress and self-efficacy are examined together, they predict life satisfaction better. The findings reveal that employees are better satisfied at work when these parameters exist. The findings imply that one's judgment over their capability will influence their action. If an individual perceives a certain stimulus as controllable, the person will intensify their emotional action, which will generate a willingness to overcome. The measure of hope is "I can attain any goals that I set for myself at my workplace", this displays the belief that one has both the will and ways to accomplish a given goal has a significant, negative influence on eustress. A 
negative correlation shows this; this suggests that highly hopeful people perceive stress at a lower rate in line with the study conducted by Sucan (2019) on the relationship between hope and perceived stress in teacher candidates; it reveals that programs related to the high level of hope to be implemented in schools may have positive effects on individuals' low stress in the examination.

The parameter "There is a way out in any challenge (problem-solving initiative)" is used to measure optimism in POB models. Optimism involves having a mindset to expect good things in future; this has a significant, negative influence on eustress. Coversano et al. [2010] describe optimism as an inclination of hope. This may have influenced the findings that a positive mindset may lower workers' perceptions of stress. Nes (2016) emphasizes that optimism is positively associated with coping strategies seeking to solve or manage stress and negatively associated with avoidance coping strategies. This implies that the respondents are more responsive toward avoidance coping strategies. The measure of subjective well-being to eustress reveals a significant, positive correlation; this implies that evaluation of one's experience can positively influence one's perception of control to the stressor. Likewise, emotional intelligence has significant, positive influence on eustress. This is in line with the study conducted by Almazrouei (2017), which reveals that emotional intelligence has positive association with employees' eustress. The hypothesis of resilience having a significant influence on eustress is rejected; this may result from resilience focusing on reinstating someone's self after an event, while eustress involves the ability to control such a situation from occurring. Likewise, the significant indicators of eustress are identified as a positive effect, meaningfulness, manageability, engagement, and positive emotions. The findings are supported by previous studies conducted by

\section{References}

Almazrouei, S.A.S. (2017). The Effect of Emotional Intelligence Dimensions on Enhancing Employees' Eustress at work, Information Management and Business Review, 9(4), 18-27.

Antonovsky, A. (1987). Unraveling the Mystery of Health: How People Manage Stress and stay well, JosseyBass publisher, San Francisco.

Australian Government Comcare. 2014. "Four Factors that Influence Resilience in the Workplace." Accessed August 9, 2016. http://www.comcare.gov.au.Bandura 2012,

Bandura, A. (2000). Cultivate self-efficacy for personal and organizational effectiveness, In: E.A. Locke (Ed), The Blackwell handbook of principles of organizational behaviour, Oxford, UK: Blackwell, 120-136.

Bandura, A. (2012). "On the Functional Properties of Perceived Self-Efficacy Revisited." Journal of Management, 38, 9-44.

Bentler, P. M. and Wu, E. J. C. (2002). EQS 6 for Windows User's Guide, Encino, CA: Multivariate Software.

Chartered Institute of Building (CIOB). (2006). Occupational stress in the construction industry. CIOB Published National Stress Survey Results. Bracknell, UK:
Simmons and Nelson (2007), Nelson and Simmons (2003), and Little, Simmons, and Nelson (2007).

\section{Conclusions}

The study assesses the effects of POB models on occupational eustress amongst construction employees in Nigeria. Although the adoption of POB models is still in its infancy, some researchers have made meaningful contributions to the study of POB models. The study focuses on unveiling the constructs of POB models that can effectively influence a healthy lifestyle of managing stress (eustress). This will enable practitioners to focus on areas that can propel positive mental health of employees in order to improve their performances and increase productivity. From the literature scan, six POB constructs and five parameters of eustress were reviewed.

The research findings revealed that self-efficacy, hope, optimism, subjective well-being, and emotional intelligence significantly influence eustress, although hope and optimism have negative correlations. This implies that those identified constructs can have a direct effect on eustress. Therefore, organizations should establish company policies that effectively drive the three positive constructs, such as self-efficacy, subjective wellbeing, and emotional intelligence, to promote employees' positive mental health and well-being. The findings revealed five parameters of eustress that influence eustress as positive effect, meaningfulness, manageability, engagement, and positive emotions. Although the study of POB models is still in its infancy, the findings expand POB theories. The results will guide project practitioners on areas to focus on to propel positive mental health amongst construction workers.

CIOB. Available at: http://www.ciob.org.uk/resources/ publications [Accessed on June 21 2012].

Chen, F.; Curran, P.J.; Bollen, K.A.; Kirby, J.; Paxton, P. (2008). An empirical evaluation of the use of fixed cutoff points in RMSEA test statistics in structural equation models. Sociological Methods Research, 36, 462-494.

Chinyio, E., Riva, S. and Hampton, P. (2018). Strategies to cope with stress among construction professionals: an integrated perspective, RICS COBRA 2018, 23-24 April 2018, RICS HQ, London, UK.

Conversano, C., Rotondo, A., Lensi, E., Della Vista, O., Arpone, F., and Reda, M. A. (2010). Optimism and its impact on mental and physical well-being. Clinical practice and epidemiology in mental health CP \& EMH, 6, 25-29.

Dailey, R. (2016). Organizational behaviour, Edinburgh Business School, Heriot-Watt University,etsglobal/EBS/media/EBS/PDFs/organisation al-behaviour-course-taster.pdf.

Diener, E. (2000). Subjective well-being: the science of happiness and a proposal for a national index, American Psychologist, 55, 34-43.

Diener, E. D., Emmons, R. A., Larsen, R. J., and Griffin, S. (1985). The satisfaction with life scale. Journal of Personality Assessment, 49, 71-75. 
Hamed, T. 2016 Sampling Methods in Research Methodology; How to Choose a Sampling Technique for Research. International Journal of Academic Research in Management (IJARM), 5. ffhal-02546796

Harter, J. K., Schmidt, F.L. and Hayes, T.L. 2002. "Business unit-level Relationship between Employee Satisfaction, Employee Engagement and Business Outcomes: A Meta-Analysis." Journal of Applied Psychology 87 (2), 268-279.

Haynes, N. and Love, P. (2004). Psychological adjustment and coping among construction project managers, Construction Management and Economics, 22(2), 129-140.

Hoe, S.L. (2008). Issues and procedures in adopting structural equation modeling technique, Journal of Quantitative Methods, 3(1), 76-83.

Jones, L. (2016). What Is Eustress? - Definition \& Examples, Retrieved from https://study.com/academy/lesson/what-is-eustressdefinition-examples-quiz.html.

Judges, T.A., Thoresen, C.J., Bono, J.E. and Patton, G.K. (2001). The job satisfaction-job performance relationship: a qualitative and quantitative review, Psychology Bulletin, 127:376-407, assessed August 10, 2016.

Leung, M.Y., Chan, Y.S. and Yu, S.W. (2012). Managing the stress of Hong Kong expatriate construction professionals in Mainland China: A focus group study exploring individual coping strategies and organizational supporting Hong Kong. Journal of Construction Engineering and Management, 1061(10): 1943-7862.

Leung, M.Y., Chan, Y.S. and Yuen, K.W. (2010). Impacts of stressors and stress on the injury incidents of construction workers in Hong Kong. Journal of Construction Engineering and Management, 136(10): 1093-1103.

Leung, M.Y., Olomolaiye, P., Chong, A. and Lam, C.C.Y. (2003). Impact of stress on estimation performance, Construction Management and Economics, UK: E\&FN Spon.

Li, C.-T., Cao, J. and Li, T.M.H. (2016) Eustress or Distress: An Empirical Study of Perceived Stress in Everyday College Life. Proceedings of the 2016 ACM International Joint Conference on Pervasive and Ubiquitous Computing Adjunct, Heidelberg, Germany, 12-16 September 2016, 1209-1217.

Little, L.M., Simmons, B.L., \& Nelson, D.L. (2007). Health among leaders: Positive and negative affect, engagement and burnout, forgiveness and revenge. Journal of Management Studies, 44, 243-60.

Lunenberg, F. C. 2011. "Self-efficacy in the Workplace: Implication for Motivation and Performance." International Journal of Management, Business and Administration 14 (1): 1-6.

Luthans, F. (2002). The need for and meaning of positive organizational behavior, Journal of Organizational Behavior, 23: 95-706.

Luthans, F., and C. M. Youssef. 2007. "Emerging Positive Organisational Behaviour." Journal of Management 33: 321-349.

Martins, A., Ramalho, N., \& Morin, E. (2010). A comprehensive meta-analysis of the relationship between emotional intelligence and health, Personality and Individual Differences, 49, $554-564$

Matejek, E. T. (2019). The explanatory role of Eustress and Distress in the relationship between Extraversion and Depression A Cross-sectional Study, Bachelor Thesis, University of Twente, Enschede.

McCann, D. 2015. "Optimism: It's role in the workplace.” This Worldwide. Accessed August 9, 2016. http://www.tmsworldwide.com.

McHugh, M. 2001. "Employee Absence: An Impediment to Organisational Health in Local Government." The International Journal of Public Sector Management 14: 43-58.

Moore JW (2016) What Is the Sense of Agency and Why Does it Matter? Frontier in Psychology, 7:1272, DOI: $10.3389 /$ fpsyg.2016.01272.

Nangia, N. and Chaturvedi, V. (2015). Understanding the role of positive stress as a mediating tool for employee performance: A conceptual insinuation, International Journal of Management and Business Studies, 5(1), 3941.

National Research Council, (2013). Subjective WellBeing: Measuring Happiness, Suffering, and Other Dimensions of Experience. Washington, DC: The National Academies Press. https://doi.org/10.17226/18548.

Nelson, D.L., \& Simmons, B.L. (2003). Health psychology and work stress: a more positive approach. In J.C. Quick and L.E. Tetrick (Eds), Handbook of Occupational Health Psychology (pp. 97-119). Washington, DC: American Psychological Association.

Nes, L.S. (2016). Chapter 51: Optimism, Pessimism and Stress, In Stress: Concepts, Cognition, Emotion and Behavior, Handbook of Stress Series, 1:405-411.

Ng, T. W. H., Eby, L. T., Sorensen, K. L., and Feldman, D. C. 2005. Predictors of objective and subjective career success: A meta-analysis. Personnel Psychology, 58: 367408.

Nunnally, J.C. and Bernstein, I.H. (2007). Psychometric Theory, McGraw-Hill, New York.

O'Sullivan, G. (2011). The Relationship between Hope, Eustress, Self-Efficacy, and Life Satisfaction among Undergraduates, Social Indicators Research, 101:155172.

Ogwueleka A.C. (2011) The critical success factors influencing project performance in Nigeria, International Journal of Management Science and Engineering Management, 6(5), 343-349, DOI: 10.1080/17509653.2011.10671182

Ogwueleka, A.C. and Ogbonna, S.N. (2018) Effect of positive organizational behaviour (POB) characteristics on construction employees' turnover in Uyo City of Akwa Ibom State, Nigeria, African Journal of Science, Technology, Innovation and Development, 10(2), 159168.

Pandey, S. (2005). Time to manage stress positively, Human Resources, January edition, 2005, 84-89.

Pandey, S. C. and Gaur, S. P. (2005). "A Positive Mental Health Model for Stress Management Interventions in Organizations: Insights from Positive Psychology", presented at 92nd Indian Science Congress, organized by Indian Science Congress Association, 
Nirma University, Ahmedabad and National Institute of Occupational Health, Ahmedabad, January 3-7, 2005.

Peterson, C. (2000). The future of optimism. American Psychologist, 55(1), 44-55. https://doi.org/10.1037/0003066X.55.1.44

Quick, J.C., Cooper, C.L., Gibbs, P.C., Little, L.M. and Nelson, D.L. (2010). Positive organizational behavior at work, Chapter 5, International Review of Industrial and Organisational Psychology, 25, 253-292.

Rees, C. S., Breen, L. J., Cusack, L., and Hegney, D. (2015). Understanding individual resilience in the workplace: the international collaboration of workforce resilience model, Frontier in Psychology, 6:73, DOI: 10.3389/fpsyg. 2015.00073.

Saunders, M., Lewis, P. and Thornhill, A. (2009) Research Methods for Business Students. Pearson, New York.

Schwarzer, R., and Jerusalem, M. 1995. "Generalized Self-Efficacy Scale." In Measures in Health Psychology: A User's Portfolio, Causal and Control Beliefs, edited by J. Weinman, S. Wright, and M. Johnson, 35-37. Windsor, UK: NFER-NELSON.

Seligman, M. and Csiksentmihalyi, M. (2000). Positive psychology, American Psychologist, 55:5-14.

Seligman, M. E. P. (2002). Positive psychology, positive prevention, and positive therapy. In C. R. Snyder \& S. J. Lopez (Eds.), Handbook of positive psychology (p. 3-9). Oxford University Press.
Seligman, M. E. P., \& Csikszentmihalyi, M. (2000). Positive psychology: An introduction. American Psychologist, 55(1), 5-14.

Simmons, B. L. (2000). Eustress at work: Accentuating the positive, Unpublished doctoral dissertation, Oklahoma State University.

Simmons, B., \& Nelson, D. (2007). Eustress at work: extending the holistic stress model. In D. L. Nelson, \& C. L. Cooper (Eds.), Positive organizational behavior (pp. 40-54). SAGE Publications Ltd, https://www.doi.org/10.4135/9781446212752.n4

Smith, S. (2015). Maximizing Optimism in the Workplace, EHS Today, Accessed August 9, 2016. http://ehstoday.com.

Snyder, C. R. (2000). Hypothesis: There is hope. In C. R. Snyder (Ed.), Handbook of hope: Theory, measures, and applications (p. 3-21). Academic Press. https://doi.org/10.1016/B978-012654050-5/50003-8Stay Well. San Francisco, CA: Jossey-Bass

Sucan, S (2019). The Relationship between Hope and Perceived Stress in Teacher Candidates, International Journal of Higher Education, 8(2), 1-6, Sciedu Press.

Synder, C.R., Harris, C., Anderson, J.R., Holleran, S.A., Irving, L.M., Sigmon, S.T., Yoshinobu, L., Gibb, J., Langelle, C. and Harney, P. (1991). The will and the ways, Journal of Personality and Social Psychology, 60, 570-585.

Tavakoli, M. (2010). A positive approach to stress, resistance, and organizational change, Procedia Social and Behavioral Sciences, 5, 1794-1798. 